
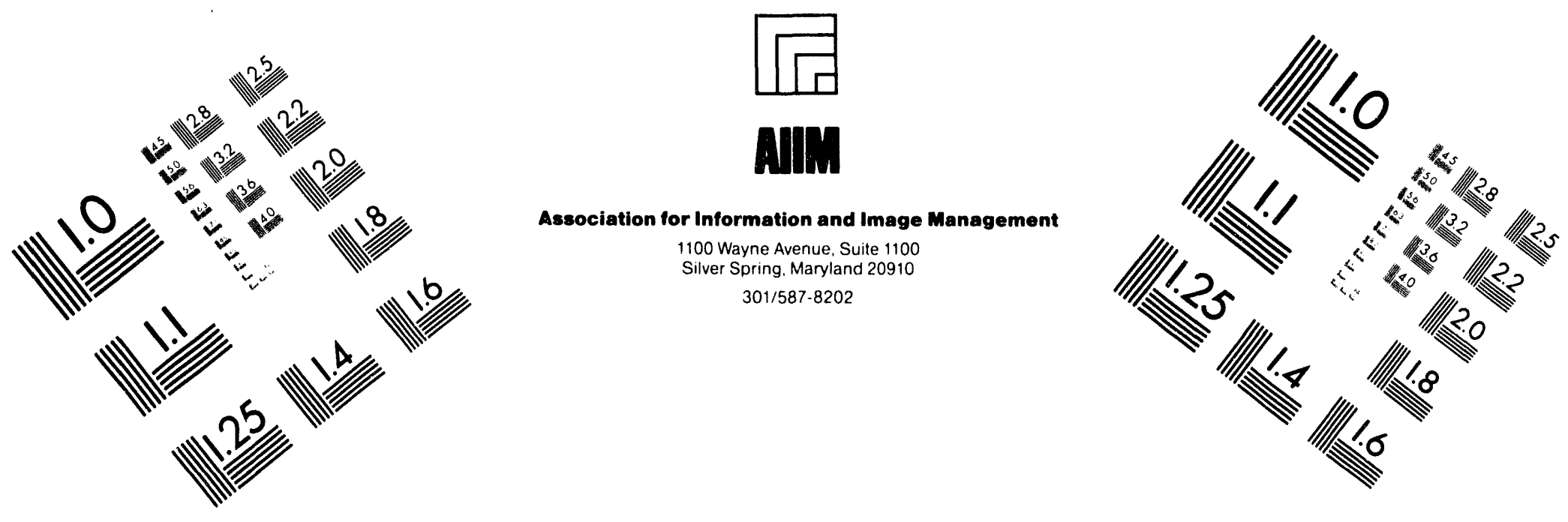

\title{
Centimeter
}

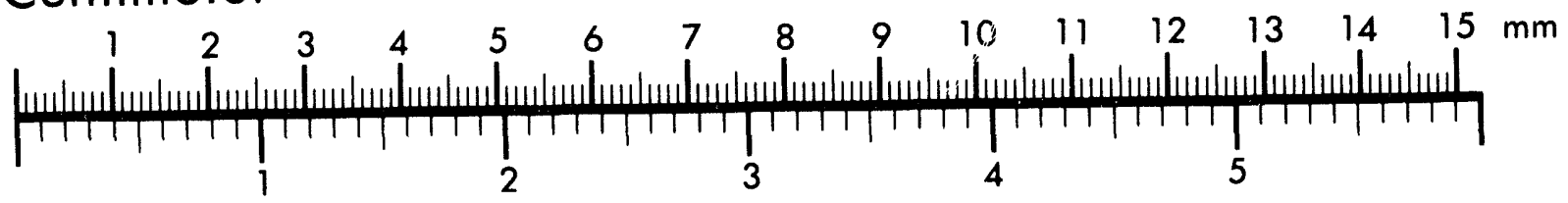

Inches
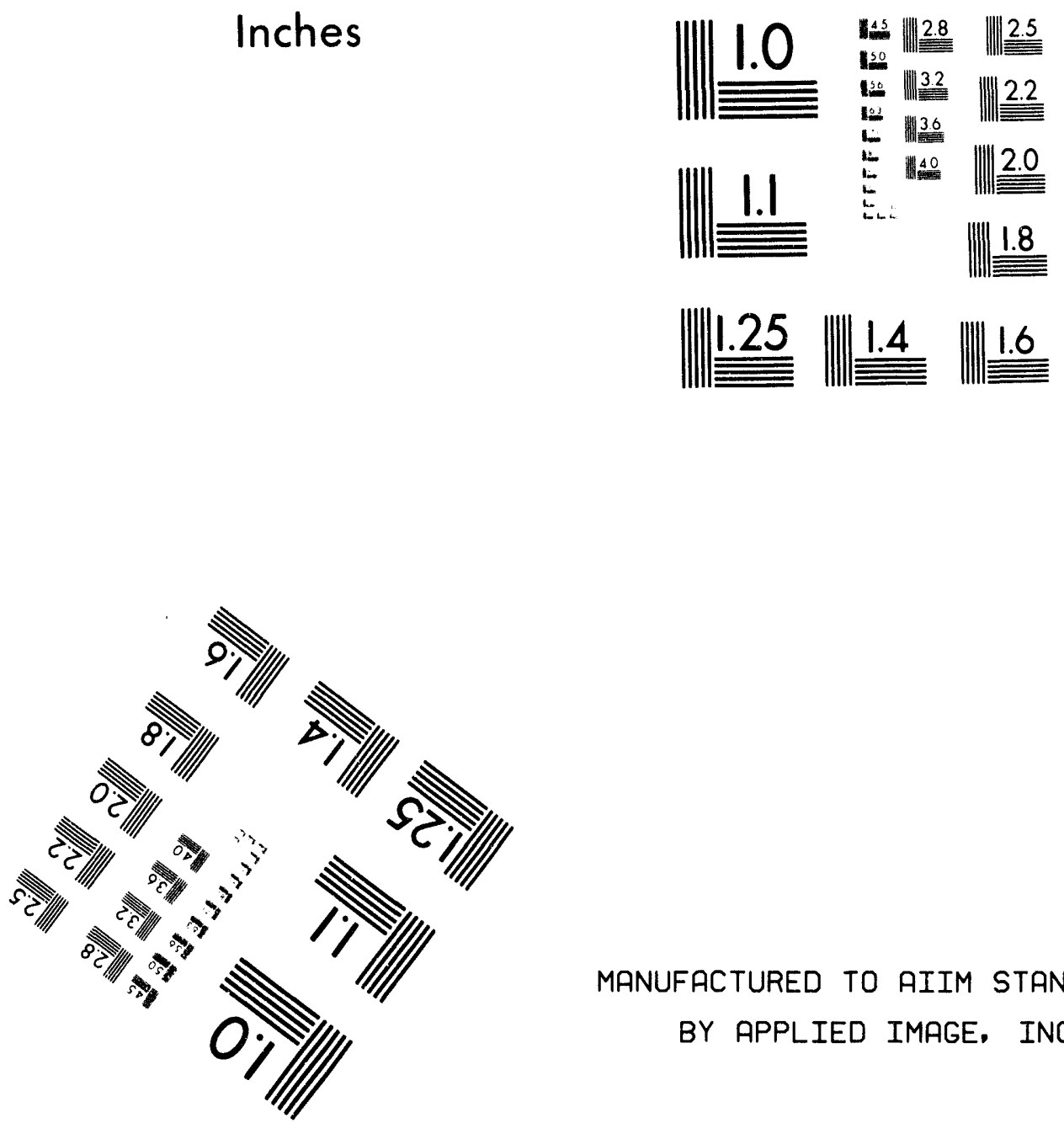

MANUFACTURED TO AIIM STANDARDS

BY APPLIED IMAGE, INC.

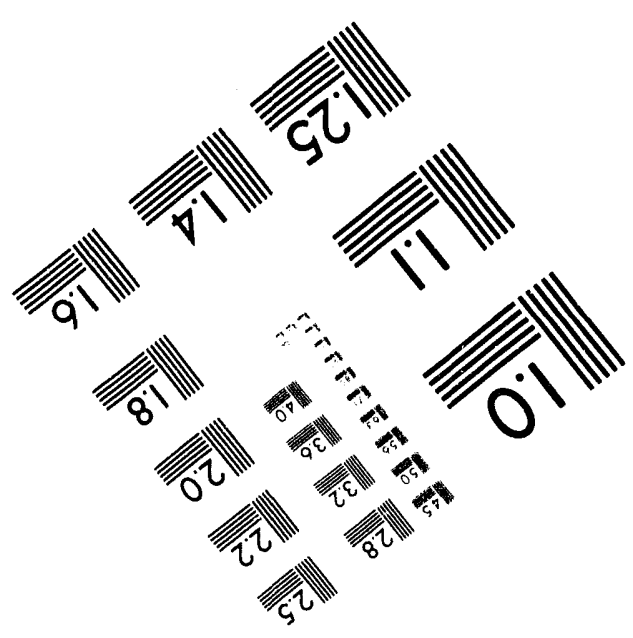



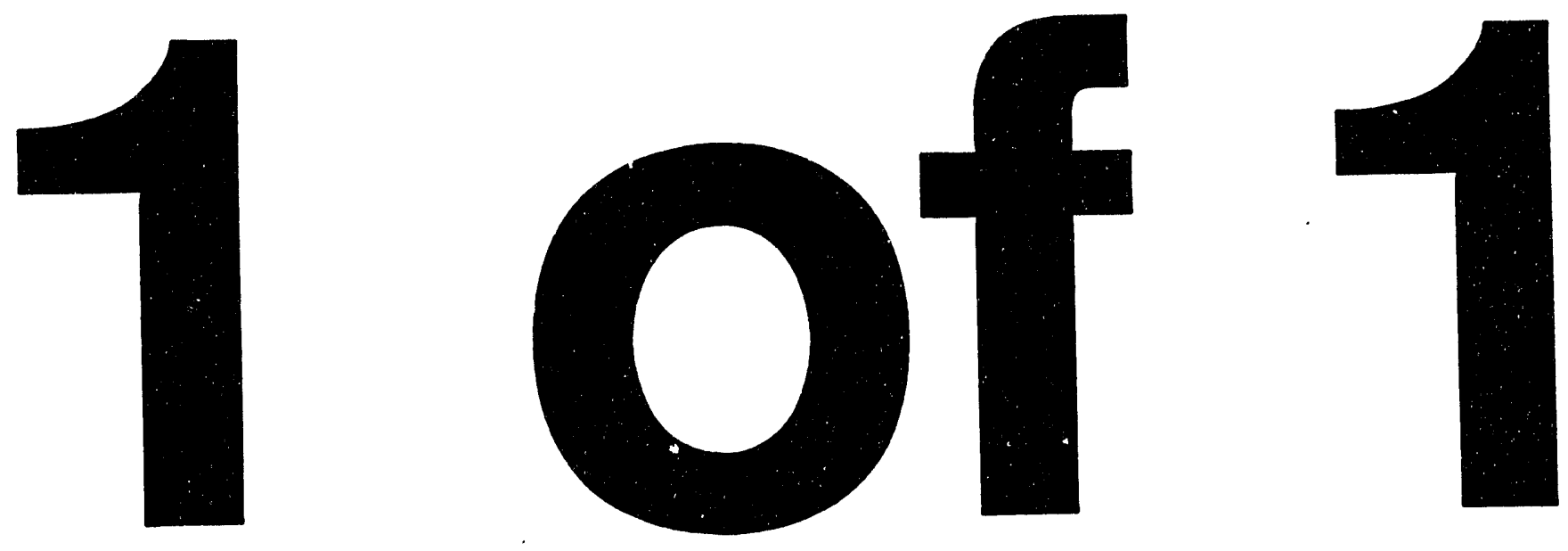

î 


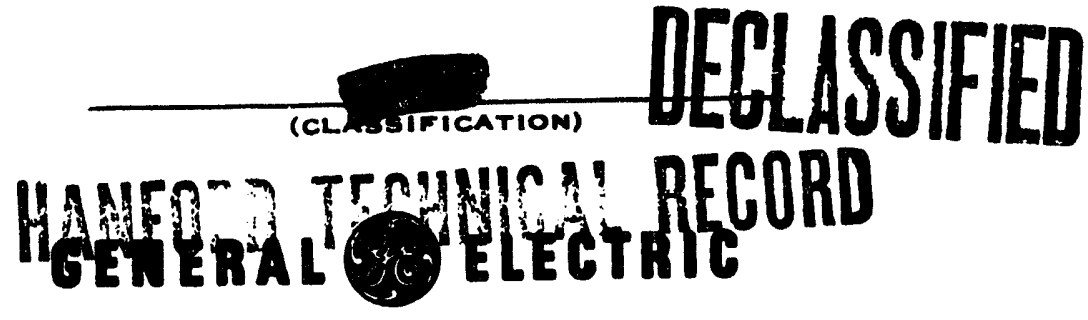

HW-T3093 C MANFORD ATOMIC PRODUCTS OPERATION - RICHLAND, WASHINGTON

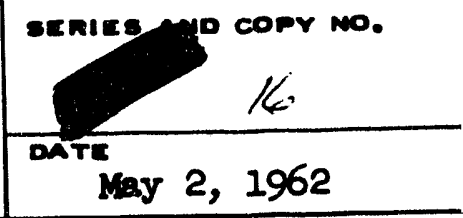

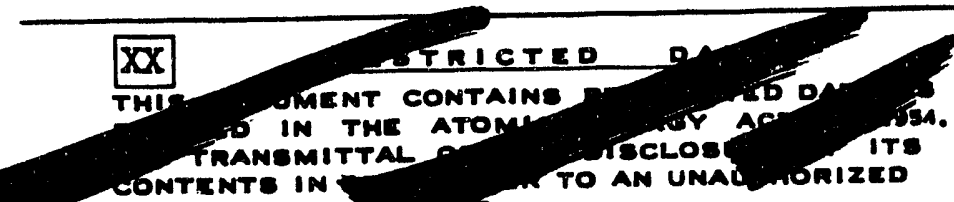
CONTENTS IN

persoon is prol.

OTHER OPFICIAL CLABEIFIED INFORMATION

THIS MATERIAL CONTAINS INFONMATION AFFECTING THE MATIONAL DEFENEE OF THE UNITED STATES WITHIN THE MEANING of THE REPIONACE LAWE. TITLE 18, U.S.C., SECS. TS AND TSA, THE TRANEMiseion on REVELATION OF WHICM IN ANY MANNER

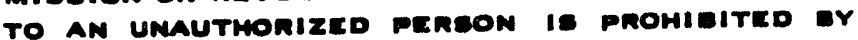
LAW.

\section{THIs DocumEnT}

To 1T. WHEm GuAnD"

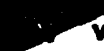
ip

E, IT MUST DE: F jERE AN UNAUTMORIZEP

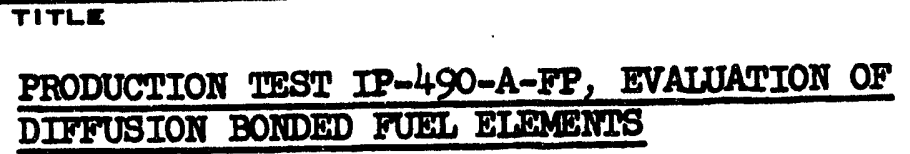

COPY RECEIVED 1:0 AREA

M. A. Clinton

MAY 311962
REIUKIV 10

TECHNICAL INFORMATION EIIES

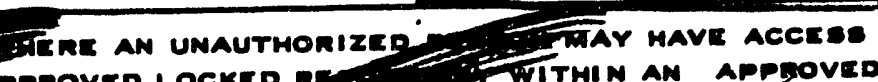

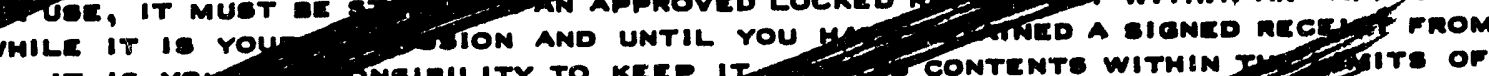

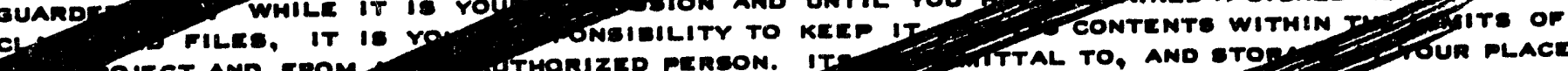

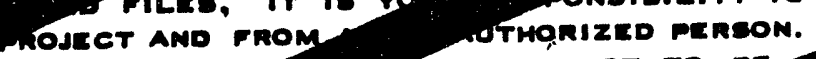

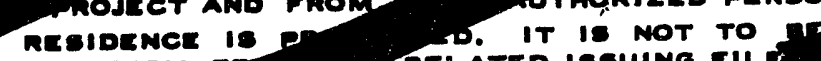
ODTAIN THEM s RELATED ISEUING FILA TO GION IN THE. H PROVIDED DELOW.

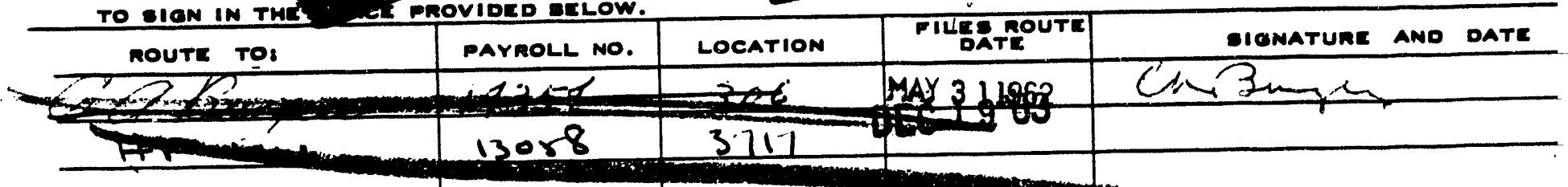

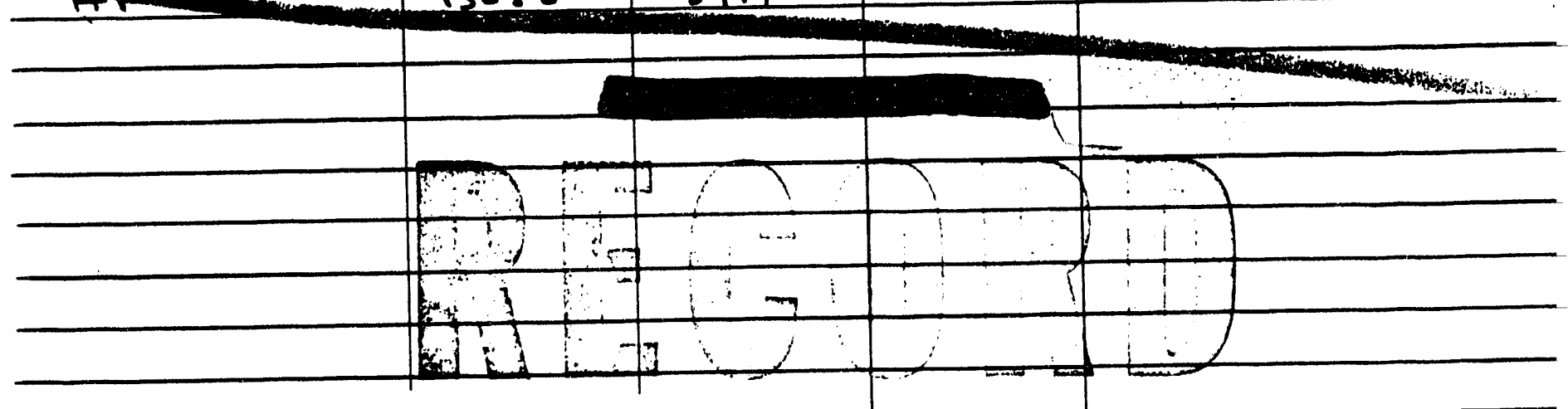

THIS DOCUMENT HAS BEEN SCANNED AND IS STORED ON THE OPTICAL DISK DRIVE 


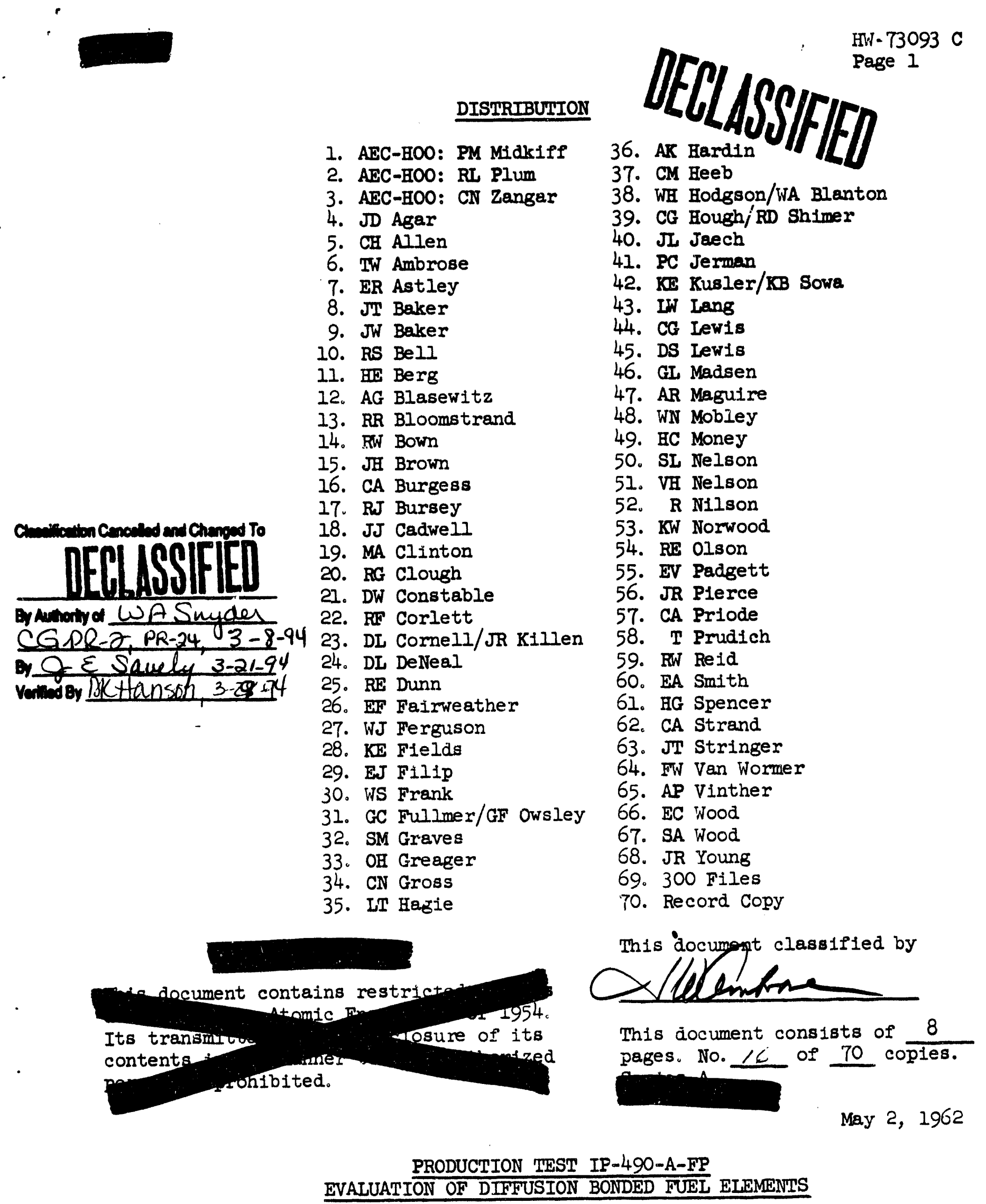

INTRODUCTION

Possible limitations to the Al-Si bonding process are being examined under an FPDIPD testing program. The results from this testing program should provide valuable 


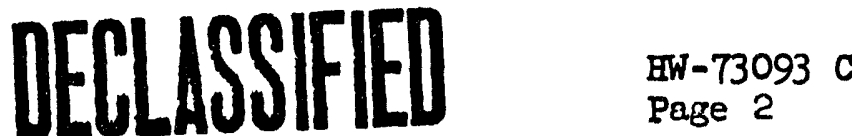

Information as to the capabilities of the Al-Si bonded fuel elements at programed operating conditions. If the Al-Si test (1) should demonstrate that the Al-Si bonding process may become limfting, then an alternate bonding process technology will be needed in a relatively short period of time.

At this time there are four potential alternate bonding processes being studied. These include: (1) Sylcor hot press, (2) Hanford hot press, (3) Banford gas pressure, and (4) Hanford hot die-sizing. The first two are ready for reactor testing, whereas the gas pressure bonding and hot die-sizing processes are still under development. This report outlines the irradiation program for the preIIminary evaluation of these processes as potential replacements for the Al-Si process.

\section{OBJECTIVE}

The objectives of this test are to determine the gross dimensional stability of hot pressed fuel and to evaluate bond quality differences between Al-Si bonds and solld state diffusion bonds.

\section{TEST SUMMARY}

Irradiation testing will be conducted at $C$ reactor and will be carried out in two parts:

Part I - Sylcor and Hanford hot press diffusion bonding processes will be compared to the Hanford Al-Si bonding process. Elghteen (18) measured monitor columns of cVNS fuel elements w1ll be 1 rradiated to an $800 \mathrm{MW} / \mathrm{T}$ goal exposure.

Part II - Hanford gas pressure and Hanford hot die sizing solid state difrusion bonding processes will be compared to the Hanford Al-Si bonding process. Again, elghteen (18) measured monitor colums of CVNS fuel elements will be irradiated to an $800 \mathrm{MWD} / \mathrm{T}$ goal exposure.

\section{BASIS AND JUSTIFICATION}

Examination of available prewirradiation data on Hanford fuel element external bond strengths indicates the strength of the Al-Si bond is relatively low. The average and maximum strengths of Al-S1 bonds are 13,500 psi and 20,000 psi, respectively, whereas, for nickel diffusion bonds, the average strength is $21,000 \mathrm{psi}$ and the maximum strength is $30,000 \mathrm{psi}$. In addition to being stronger, the nickel diffusion bond is reported to be tougher. (2) The process will permit close control of can wall thickness and will increase the uranium to aluminum weight ratio as a result of replacing the equivalent of the Al-S1 bonding annulus with uranium.

The ultimate limit of the Al-SI bonding process has never been determined, and,

(1) HW-65870-C, "Production Test IP-344-A-FP, Evaluation of Al-Si Bond Characteristics", M. A. Clinton, July 10, 1961.

(2) HW-65759, "Proposed Sol1d State Diffusion Bonding (SSDB) Process-Gas Pressure Bonding", E. A. Veakley, June 22, 1961. 
if the Al-Si bonds undergoing evaluation at high specific powers and exposures (3) indicate any deficiencies it may be necessary to develop a replacement process. The nickel diffusion bond is being developed and evaluated as a replacement for the Al-Si process should one be required.

\section{TEST DEIATIS}

1. Reactor - C Reactor will conduct both parts of this production test.

2. Material

\section{A. Fuel Elements}

1. Geometry - The CVNS fuel geometry will be utilized in both parts of this test.

2. Fabrication - Specific detalls concerning the fabrication and exreactor testing may be found in the test design document. (4) Aluminum components will be fabricated from X-8001 aluminum alloy. Fuel cores for Part I will be rolled dingot. Either ingot or dingot fuel cores may be utilized for Part II.

3. Nominal Dimensions - The following table shows various dimensions for the bare cores and the Iinished fuel elements:

\begin{tabular}{|c|c|c|c|c|}
\hline A & $\begin{array}{l}\text { anford } \\
\text { IIP }\end{array}$ & $\begin{array}{l}\text { anford } \\
\text { GPB }\end{array}$ & $\begin{array}{l}\text { Hanford } \\
\text { HDS }\end{array}$ & $\begin{array}{c}\text { Sylcor } \\
\text { EP }\end{array}$ \\
\hline .4 & $\begin{array}{l}.427 \\
.400\end{array}$ & $\begin{array}{l}1.432^{\prime \prime} \\
.437^{\prime \prime} \\
8.365^{\prime \prime}\end{array}$ & $\begin{array}{r}1.4 \\
.4 \\
8.6\end{array}$ & \\
\hline
\end{tabular}

b) Nominal Finished Element OD
Nominal Finished Element ID Nominal Finished Element Length Nominal Rib Height Maximum Circumscribed Circle

$\begin{array}{lllll}1.499^{\prime \prime} & 1.494^{\prime \prime} & 1.494^{\prime \prime} & 1.494^{\prime \prime} & 1.494^{\prime \prime} \\ 0.375^{\prime \prime} & 0.37 \text { " }^{\prime \prime} & 0.375^{\prime \prime} & 0.375^{\prime \prime} & 0.375^{\prime \prime} \\ 8.965^{\prime \prime} & 9.000^{\prime \prime} & 9.000^{\prime \prime} & 9.000 " & 9.080 " \\ 0.082^{\prime \prime} & 0.082^{\prime \prime} & 0.082^{\prime \prime} & 0.082^{\prime \prime} & 0.082^{\prime \prime} \\ 1.660^{\prime \prime} & 1.660^{\prime \prime} & 1.660^{\prime \prime} & 1.660 " & 1.660 "\end{array}$

4. Self-Supports - The self-support rails will be ultrasonically welded to the fuel element and will be simjlar in appearance to those on the presently used CIVNS element. (5)

(3) Op cit, $\mathrm{HW}-65870 \mathrm{~m}$

(4) HW-73093-A, "Design of Production Test IP-490-A-FP, Evaluation of Diffusion Bonded Fuel Elements", W. H. Hodgs on and M. A. Clinton, March 26, 1962.

(5) HW-61669-C, "PT-IP-272-A-FP, Pilot Test of Self-Supported Fuel Elements in Ribless Zirconium Process Tubes, R. E. Hall and D. H. Curtiss, July 27, 1959. 
5. Pre-Irradiation Testing, Measurements, and Mariking

The following tests and measurements are to be made on cores and fuel elements prior to irradiation:

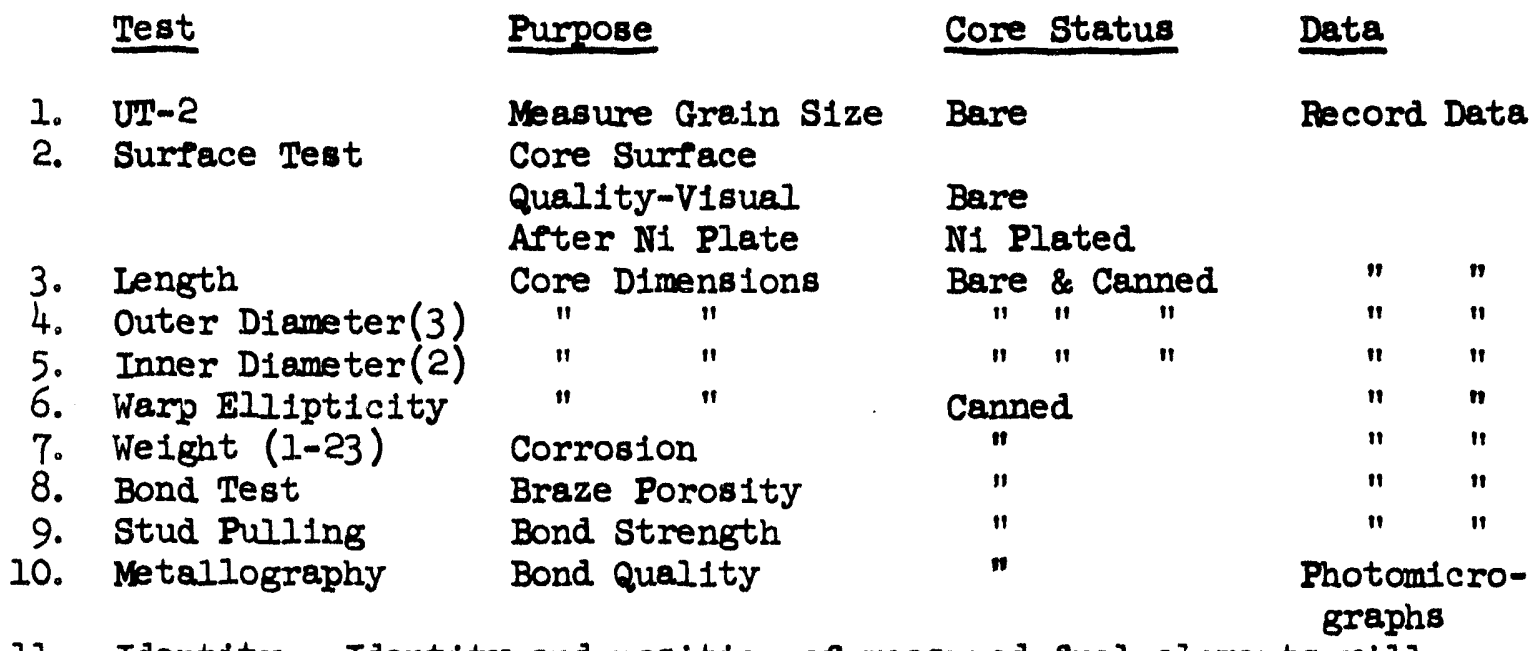

11. Identity - Identity and position of measured fuel elements will be recorded by a series and position number stamped on the base of each fuel element.

6. Column Make-Up - Columns will be made by alternating fuel elements from two of the three groups in each part. To simplify the description, the following code will be used:

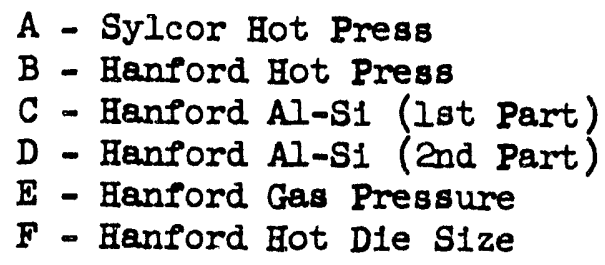

The elements will be made into columns as listed below:

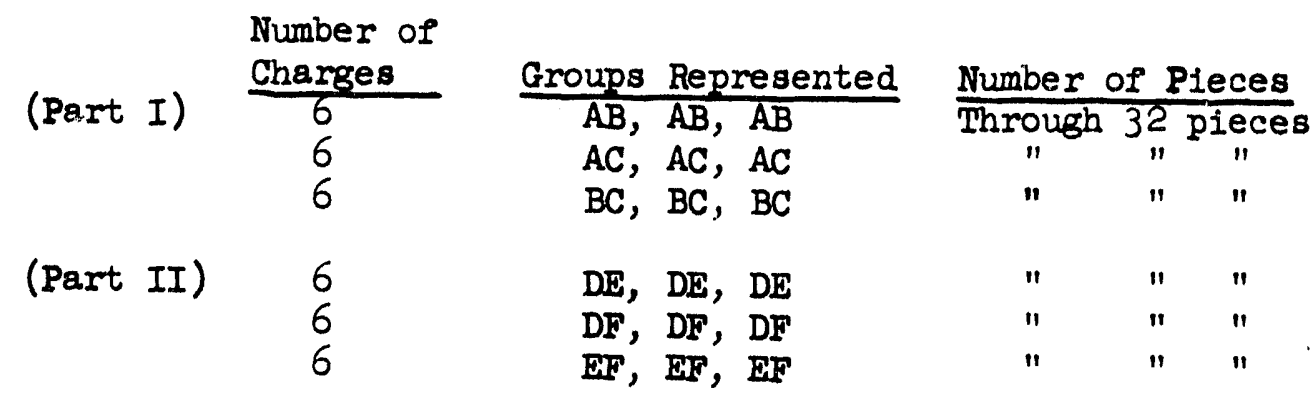

Thus, in the event one type should prove dimensionally unstable or rupture prone, the test of the other types will not be in jeopardy and the comparison of the remaining processes will still be on a statistical basis. Columns will be placed in specially identified shipping pallets in charging order.

B. Process Tubes

Smooth-bore $\mathrm{Zr}-2$ process tubes installed into $\mathrm{C}$ reactor under authorlzation 
of IP-272-A ${ }^{(6)}$ will be utilized in this test.

C. Durmies and Seating

The downstream dumy pattern and seating method in use for cIvis elements at the time this test is charged shall be used.

D. Thermocouple Probes - Not required for this test.

E. Probolog - Not required for this test.

3. Irradiation

A. Charging

All test columns will be charged in numerical order with piece number one downstream. Each column will have the fuel identification number (series and/or lot number) recorded opposite the tube number on the front face sequence sheet. Charging of material for both parts of this test will be followed by a representative of Research and Engineering. Test columns will be charged into locations which will provide similar irradiation conditions for all tubes. Iocations will be selected by the assigned Process Engineer and Physicist with the concurrence of the test author and will be selected from those tubes nearest goal exposure.

Hand charging is authorized in order to minimize damage to the selfsupports if a satisfactory charging machine is not available.

B. Data - No special operating data recordings are planned.

C. Goal Exposure

Goal exposure for all test columns will be $800 \mathrm{MWD} / \mathrm{T}$. Goal exposure changes may be made by request from the test author with the concurrence of the reactor processing manager.

D. Discharge

All columns will be monitor columns and will require special pickup and shipment to the 105-C MFF for post;irradiation examination and measurement. All test columns containing one type may be discharged prior to reaching goal exposure after two failures have occurred in that type provided all columns can be specially picked up.

E. Operating Limits

The operating conditions and limits which apply to the CIVN-S geometry will be applicable to this materlal. Existing Process Standards will be used as the basis for all operating conditions and limits not specifically covered within this test authorization.

(6) Op cit HW-61669-C (69 tubes of I. D. $1.681 \pm .005)$. 
4. General

\section{DECLISSFIED \\ Page 6}

A. Schedule

Puel elements for Part I have been fabrlcated and are ready for reactor charging. Reactor charging is requested for the first outage following approvel of this test.

Further development work on Part II fabrication processes w1]I require 3 to 4 months. Fuel elements for evaluation under Part II are expected. to be ready for charging about August, 1962.

B. Duration

Irradiation of each Part of this test will require about 4 months. This test authorization w1ll expire on December 1, 1963.

C. Post-Irradiation Examination

All pre-measured fuel elements will:

1) Be weaseled and visually inspected for surface conditions,

2) be measured for length, warp, and diameter changes $\left(O D_{1}, O D_{2}, O D_{3}\right.$, $\mathrm{ID}_{5}$ and $\mathrm{ID}_{7}$ ),

3) have weight recorded (pieces 1 - 23),

4) be bond tested if equipment is available.

Selected pieces may be set aside for stripping and bare core measurements - depending on either the preliminary visual examination results or a later analysis of the measurement data. Also, selected elements may be sent to Radiometallurgy for destructive examination.

D. Costs

The primary outage time losses resulting from this test will be associated with charge-discharge and special pickup. All incremental costs associated with the performance of this test may be charged to XXXX-5R24$\mathrm{XXX} .73$. Outage time requirements are listed below for scheduling purposes:

$\begin{array}{llc}\text { Job } & \text { Processing Time } & \text { Elevator Time } \\ \text { Charge } & 1 / 2 \mathrm{mh} / \text { tube } & \frac{1 / 4 \mathrm{hr} / \text { tube }}{1 / 2 \mathrm{mh} / \text { tube }}\end{array}$

E. Hazards

No new or unusual hazards are associated with this test.

\section{RESPONSIBILITIES}

\section{Fuels Preparation Department}

Responsibilities assigned to the Fuels Preparation Department are authorized by HW-73093-B, which in brief, authorizes fabrication of the test material and assigns responsibilities within Fuels Preparation Department necessary to carrying out this production test. 


\section{DECLLSSFF|FED}

Irradiation Processing Department

Research and Bngineering Section

Process and Reactor Development Sub-Section - shall be responsible for coordination of the test, analysis of operating data, reporting of inreactor performance, and for provision of bases for operating limits.

Process Technology Sub-Section - shall be responsible for providing assistance to both the Processing Operation and the Process and Reactor Development Sub-Section in pre-shutdown scheduling, in charging the test materials, in selection of test channel locations, for forwarding operating data to the author, and for specification of operating limits.

Operational Physics Sub-Section - shall be responsible for providing assistance in selecting test channel locations, and for reactivity adjustments as required by this test.

Component Testing Unft - shall be responsible for post-irradiation fuel element examination and measurements.

\section{Manufacturing Section}

Production Scheduling - shall be responsible for scheduling discharge of the test material.

C Reactor Operation - shall be responsible for scheduling, for operational safety and production continulty of the reactor, and for charging the test mäterial.

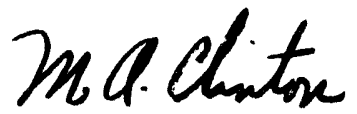

M. A. Clinton

Reactor Fuels Unit

Process \& Reactor Development Research and Engineering Section IRRADIATION PROCESSING DEPARTMENTI

MAC: $g b$ 
A is Aderm

J. 范. Brown, Manager

Process and Reactor Development Subsection IRRADIATION PROCESSING DEPARTMEANT

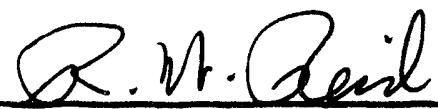

R. W. Reid, Manager

Process Technology Subsection

IRRADIATION PROCESSING DEPARTMENTT

GC Jullmer

G. C. Fullmer, Manager

Operational Physics Subsection

IRRADIATION PROCESSING DEPARIMENI

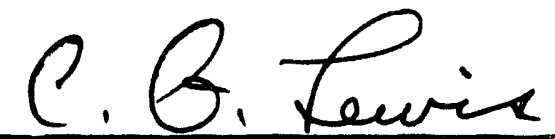

C. G. Lewis, Manager

Testing Subsection

IRRADIATION PROCESSING DEPARTMENT

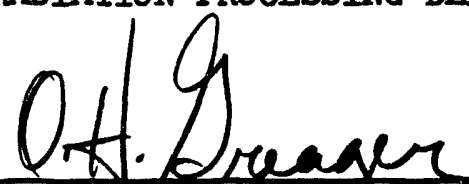

0. H. Greager, Managar

Research and Engineenting Section IRRADIATION PROCESSTIG DEPARTMENT
MoyE. D. Dunn, Manger

C Processing Operation

IRRADIATION PROCESSING DEPARTMENI

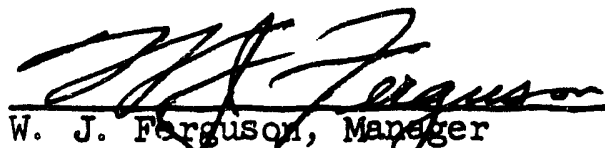

B-C Reactor Operation

IRRADIATION PROCESSIIVG DEPARTMEANT

$1200 \mathrm{cosh}$

C. A Prloce, Manager

Production Operation

IRRADIATION PROCESSING DEPARTMEGNT

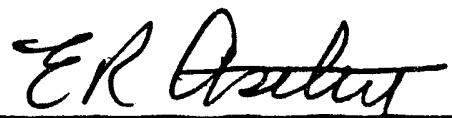

E. R. Astley, Manage

Applied Reactor Englheering IRRADIATION PROCESSING DEPARTMENT $f \frac{1}{0}<-0$ cinl

o. C. Schroeder, Manager

Manufacturing Section

IRRADIATION PROCESSING DEPARTMENTI 

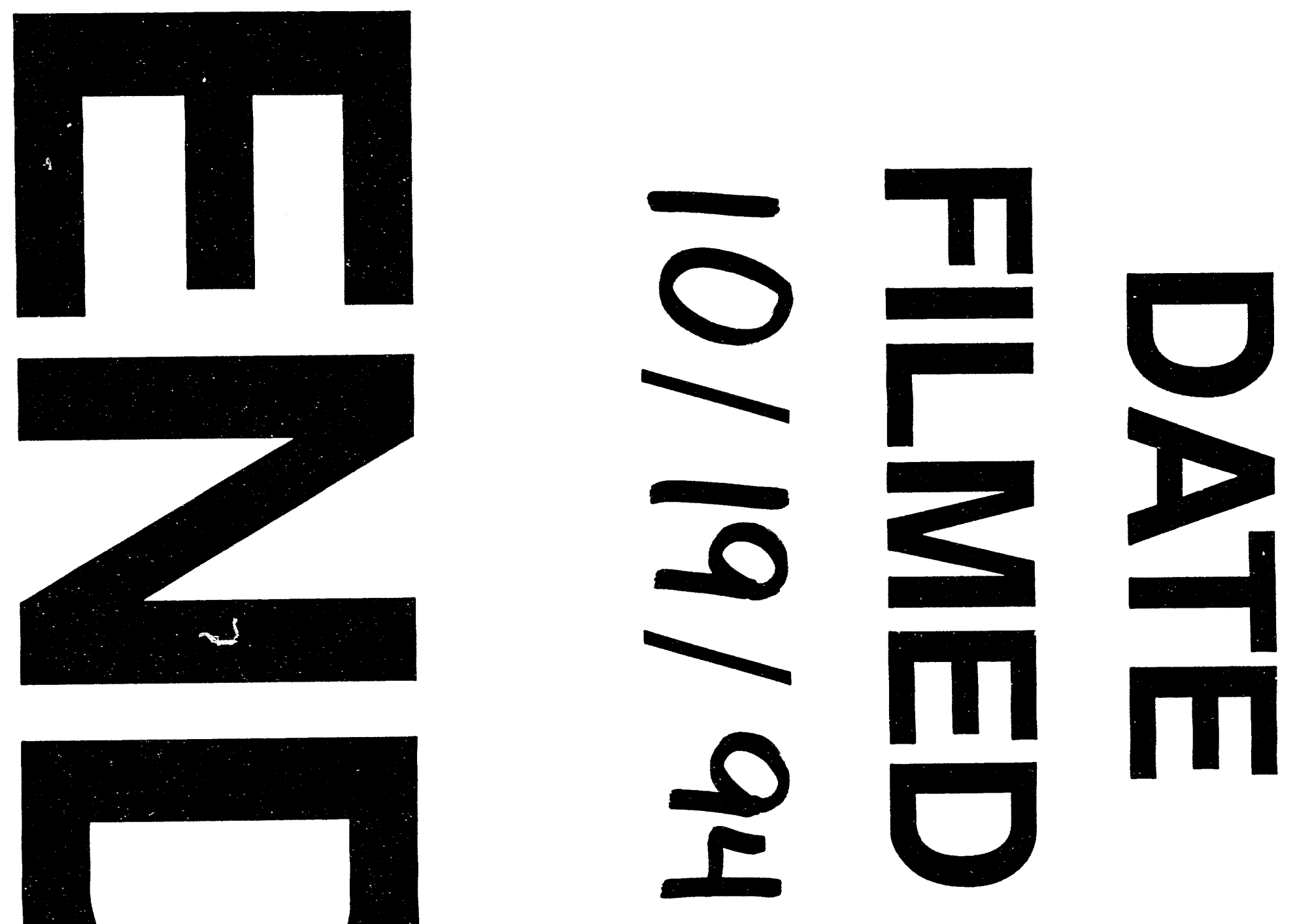
